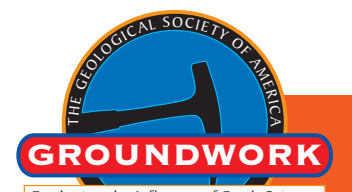

GROUNDWORK: FURTHERING THE INFII

\title{
Advocates for cold-blooded dinosaurs: The new generation of heretics
}

Timothy L. Clarey, Delta College, Dept. of Geology, 1961 Delta Road, University Center, Michigan 48710-0002, USA, tlclarey@delta.edu

\section{INTRODUCTION}

Robert Bakker (1986) branded himself and a small group of groundbreaking and upstart paleontologists in the 1960s and 1970s "heretics" because they challenged the mainstream view of dinosaurs as slow, sluggish, and cold-blooded reptiles. This view, that dinosaurs were warm-blooded, active, bird-like creatures, much different than extant reptiles of today, is now widely accepted by scientists and the public alike. Yet, this viewpoint has been challenged in recent years by a small but active minority group of researchers, herein described as the new generation of heretics. This paper concentrates on some of the newer evidence suggesting that dinosaurs might have been cold-blooded or ectothermic. Unfortunately, the proof of whether an animal is endothermic or ectothermic is found only in soft tissue anatomy, which is not well preserved and is extremely rare in the fossil record (Ruben and Jones, 2000).

\section{BONES, NASAL PASSAGES, AND SOFT-TISSUE DATA AS INDICATORS OF DINOSAUR METABOLISM}

Bone histology involves study under a microscope of thinsections of bone tissue. Two types of compact bone structure have been identified in these studies: lamellar-zonal and fibrolamellar. Lamellar-zonal bone has a layered appearance with lines of arrested growth (LAGs), or growth lines, and is poorly vascularized, with few Haversian canals, like most modern reptiles and amphibians (Ruben and Jones, 2000). The age of such animals can be determined by counting the growth rings or LAGs in the bone, similar to counting tree rings. Fibro-lamellar bone has a fibrous, woven appearance and is highly vascularized, with numerous Haversian canals (Reid, 1997). This type of bone, which contains fewer LAGs, is found in birds, mammals, and most dinosaurs.

Histologic study of dinosaur bone has been hailed as "proof" of dinosaur endothermy because dinosaurs commonly exhibit the same highly vascularized, fibro-lamellar bone structure as seen in mammals (Bakker, 1986; Reid, 1997). Ruben and Jones (2000) argue that this type of bone cannot be used as absolute proof of metabolic rate, pointing out that this interpretation is inconsistent with a variety of paleontological and biological data. Fibro-lamellar bone is present in some modern turtles, crocodiles, and lizards, and some dinosaurs contain both fibrolamellar and lamellar-zonal structures (Reid, 1997). A study by Tomasz Owerkowicz (Morell, 1996) has shown that the posses-

doi: 10.1130/GSAT01701GW.1. sion of highly vascularized bone merely means the animal was active and not necessarily endothermic. Owerkowicz raised two savannah monitor lizards and exercised one daily while letting the other remain inactive. After a few years, he killed the pair and examined their respective bone microstructure. He found that the active lizard had a bone microstructure that was highly vascularized, mimicking an endothermic animal and containing numerous Haversian canals. The inactive lizard had a poorly vascularized microstructure, typical of modern ectothermic animals. His study only "proved" that dinosaurs were active.

Ruben and Jones (2000) believe that the presence of respiratory turbinates makes a better "proof" of endothermy. Ninetynine percent of endothermic animals have turbinates or coils of membrane-covered cartilage or bone in their nasal passages. These structures significantly reduce water and heat loss associated with rapid rates of lung ventilation as needed in endothermic animals. Although cartilaginous turbinates may not always be preserved as fossils, Ruben's team (1996) found that the presence of turbinates is directly correlated with larger nasal cavities in modern endothermic animals. They suspect that larger nasal passages in endotherms serve to accommodate greater lung ventilation rates and provide the room necessary to house the respiratory turbinates. Ruben et al. (1996) conducted CT-scans on several dinosaur skulls, including two theropods, Tyrannosaurus (Nanotyrannus) and Ornithomimus, and one ornithischian, Hypacrosaurus. These dinosaurs showed narrow nasal cavities, indicative of modern ectothermic animals, with little room for respiratory turbinates. Ruben et al. (1996) interpret this as strong evidence for low lung ventilation rates, implying ectothermy or near-ectothermy.

Ruben et al. (1997, 1999) also found limited soft-tissue and skeletal support for ectothermy in theropod dinosaurs. They interpreted soft-tissue impressions of the abdominal cavity in the theropod dinosaur Scipionyx samniticus as a hepatic piston, diaphragm-assisted, lung ventilation system similar to modern crocodiles. The attachment style of the intestines and colon also indicates that the avian-style abdominal air sacs and the flow-through air sac lung were not present in Scipionyx.

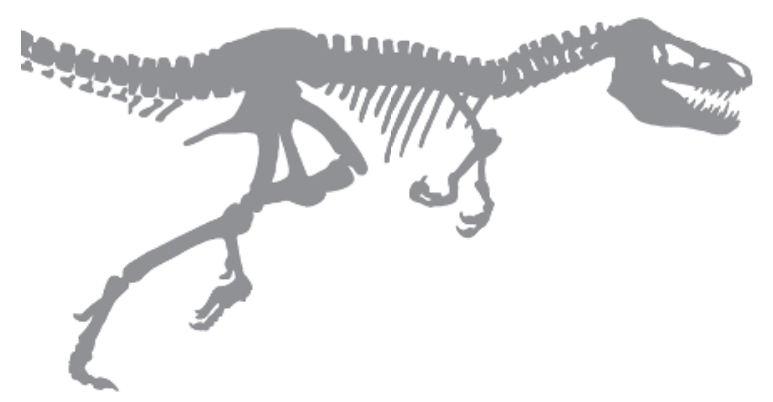


In their analysis of the Early Cretaceous theropod Sinosauropteryx, Ruben and colleagues studied the fossilized outline of the abdominal cavity, finding complete thoracic-abdominal separation with a vertically oriented partition that appears coincident with the dome-shaped anterior surface of the liver. This condition is not found in mammals today and is more consistent with the lung system of modern crocodiles. They concluded that the crocodilian-style lung system and the lack of respiratory turbinates indicate that theropod dinosaurs probably maintained ectotherm-like resting metabolic rates. They also postulated that theropod dinosaurs had the capability of expanding their lung capacity to approach the ventilation levels of mammals during periods of high activity.

\section{DINOSAUR GROWTH RATES AND METABOLISM}

Growth rate is usually influenced by an organism's metabolism. Recent studies of dinosaur growth rates have shown most species experienced slow growth rates initially, followed by a period of accelerated growth, and finally, slowed or reduced growth rates in adulthood. This is called a "sigmoidal" growth curve (Erickson et al., 2001) and is typical of most vertebrate animals. Growth rates were determined by counting "growth rings" in bones (Erickson et al., 2001). In older individuals, where medullar expansion caused hollowing of the bones and growth ring loss in many of the adult bones, Erickson et al. (2004) used fibulae, ribs, cranial bones, and other non-weight-bearing bones for their analyses. They believe these bones do not lose the growth ring pattern with age. Carpenter (1999), however, disagrees. He believes that rib bones do not always show accurate growth rings and should be used for minimum ages only. Recent research by Yao et al. (2002) found that growth rings in juvenile ornithomimid dinosaurs did disappear in adult rib bones, reaffirming the minimum age determination of Carpenter. Therefore, all interpretations concerning the ages of adult dinosaurs and their growth rates must be accepted with some caution. Was $T$. rex "Sue" really 28 years old as Erickson et al. (2004) suggested, or was he/she really 40 ? No one can be sure at this point. T. rex "Sue," as one of the largest specimens ever found, was probably one of the oldest of his/her kind.

Does the growth rate data indicate dinosaurs were warmblooded? Not necessarily. Erickson et al. (2001) found dinosaur growth rates were considerably slower than those for birds, but still much faster than modern reptiles. They concluded that small dinosaurs grew at rates similar to modern marsupials, while larger dinosaurs grew faster, at rates approaching placental mammals and precocial birds. As Owerkowicz observed (Morell, 1996), warmer temperatures in the Mesozoic Era could have had ectothermic dinosaurs growing at near mammalian rates.

In a separate study, Erickson et al. (2004) showed that tyrannosaurid dinosaurs had maximal growth rates between 33\%-52\% of the rates expected for other dinosaur groups. They concluded that the growth pattern of theropod dinosaurs, the purported ancestors to birds, was closer to marsupials and reptiles instead of comparably sized altricial birds. These data seem to take tyrannosaurids and dromaeosaurids a step back from warm-bloodedness (and birds) and not closer, as most paleontologists insist.

Additional support for dinosaur ectothermy comes from Barrick (2000). He calculated that a 7-ton, plant-eating, ectothermic Triceratops would only have to consume the same amount of food as a modern horse. By contrast, a similar-sized endothermic Triceratops would have needed to eat nearly 24 hours a day to maintain its metabolic requirements. Carnivores like a 7-ton ectothermic T. rex would have only needed the equivalent of a single adult hadrosaur per year, whereas an adult endothermic T. rex would have needed to consume almost one hadrosaur per week. Getting enough food each day into an endothermic, 40-ton vegetarian sauropod, with their poor dentition and tiny heads, would have been an even more difficult task.

\section{CONCLUSIONS}

It is too soon to conclude that all dinosaurs were warmblooded. Recent studies of bone histology, nasal passages, growth rates, and soft-tissue data seem to indicate that some or all dinosaurs may have been ectothermic. They were active animals, without a doubt, growing at rates approaching those of mammals. How much of this growth rate was due to warmer Mesozoic temperatures is unknown.

When educating students and the public, geoscientists must be careful not to advocate only the prevailing viewpoint. Dinosaurs remain a popular and important source of fascination for children and adults alike. New discoveries are reported by the news media nearly every week. We can use this popularity to our advantage. Dinosaurs are an excellent avenue by which we can introduce other aspects of geology (such as anatomy, biostratigraphy, geologic time, and tectonics) to students and the general public (Padian, 1988). The irony is that the 1960 s and 1970s generation of heretics has become the "establishment," and a new generation of heretics has emerged.

\section{REFERENCES CITED}

Bakker, R.T., 1986, The Dinosaur Heresies: New Theories Unlocking the Mystery of the Dinosaurs and Their Extinction: New York, William Morrow and Company, $481 \mathrm{p}$.

Barrick, R., 2000, The Thermodynamics of dinosaurs, in Paul, G., ed., The Scientific American Book of Dinosaurs: New York, St Martin's Press, p. 310-322.

Carpenter, K., 1999, Eggs, Nests, and Baby Dinosaurs: A Look at Dinosaur Reproduction: Bloomington, Indiana University Press, p. 336.

Erickson, G.M., Rogers, K.C., and Yerby, S.A., 2001, Dinosaurian growth patterns and rapid avian growth rates: Nature, v. 412, p. 429-432, doi: 10.1038/35086558.

Erickson, G.M., Makovicky, P.J., Currie, P.J., Norell, M.A., Yerby, S.A., and Brochu, C.A., 2004, Gigantism and comparative life-history parameters of tyrannosaurid dinosaurs: Nature, v. 430, p. 772-775, doi: 10.1038/nature02699.

Morell, V., 1996, A cold, hard look at dinosaurs: Discover, v. 17, no. 12, p. 98-108.

Padian, K., 1988, New discoveries about dinosaurs: Separating the facts from the news: Journal of Geological Education, v. 36, p. 215-220.

Reid, R.E.H., 1997, Dinosaurian physiology: The case for "intermediate dinosaurs," in Farlow, J.O., and Brett-Surman, M.K., eds., The Complete Dinosaur: Bloomington, Indiana University Press, p. 449-473.

Ruben, J.A., and Jones, T.D., 2000, Selected factors associated with the origin of fur and feathers: American Zoologist, v. 40, p. 585-596, doi: 10.1668/00031569(2000)040[0585:SFAWTO]2.0.CO;2.

Ruben, J.A., Hillenius, W.J., Geist, N.R., Leitch, A., Jones, T.D., Currie, P.J., Horner, J.R., and Espe, G., III, 1996, The metabolic status of some Late Cretaceous dinosaurs: Science, v. 273, p. 1204-1207.

Ruben, J.A., Jones, T.D., Geist, N.R., and Hillenius, W.J., 1997, Lung structure and ventilation in theropod dinosaurs and early birds: Science, v. 278, p. 12671270, doi: 10.1126/science.278.5341.1267.

Ruben, J.A., Dal Sasso, C., Geist, N.R., Hillenius, W.J., Jones, T.D., and Signore, M., 1999, Pulmonary function and metabolic physiology of theropod dinosaurs: Science, v. 283, p. 514-516, doi: 10.1126/science.283.5401.514.

Yao, J.-X., Zang, Y., and Tang, Z.-L., 2002, Histological study on the Late Cretaceous Ornithomimid and Hadrosaurid: Acta Palaeontologica Sinica, v. 41, p. 241-250.

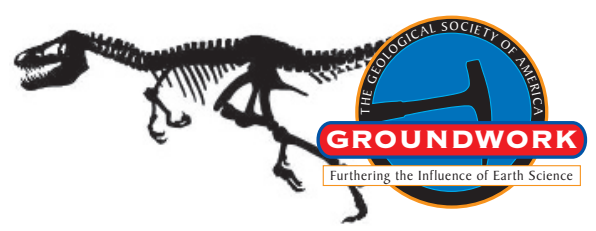

JANUARY 2007, GSA TODAY 


\section{Visit the NEW GSA Journals' Home Pages}

\section{Simpler Navigation • Greater Search Features • Improved Content}

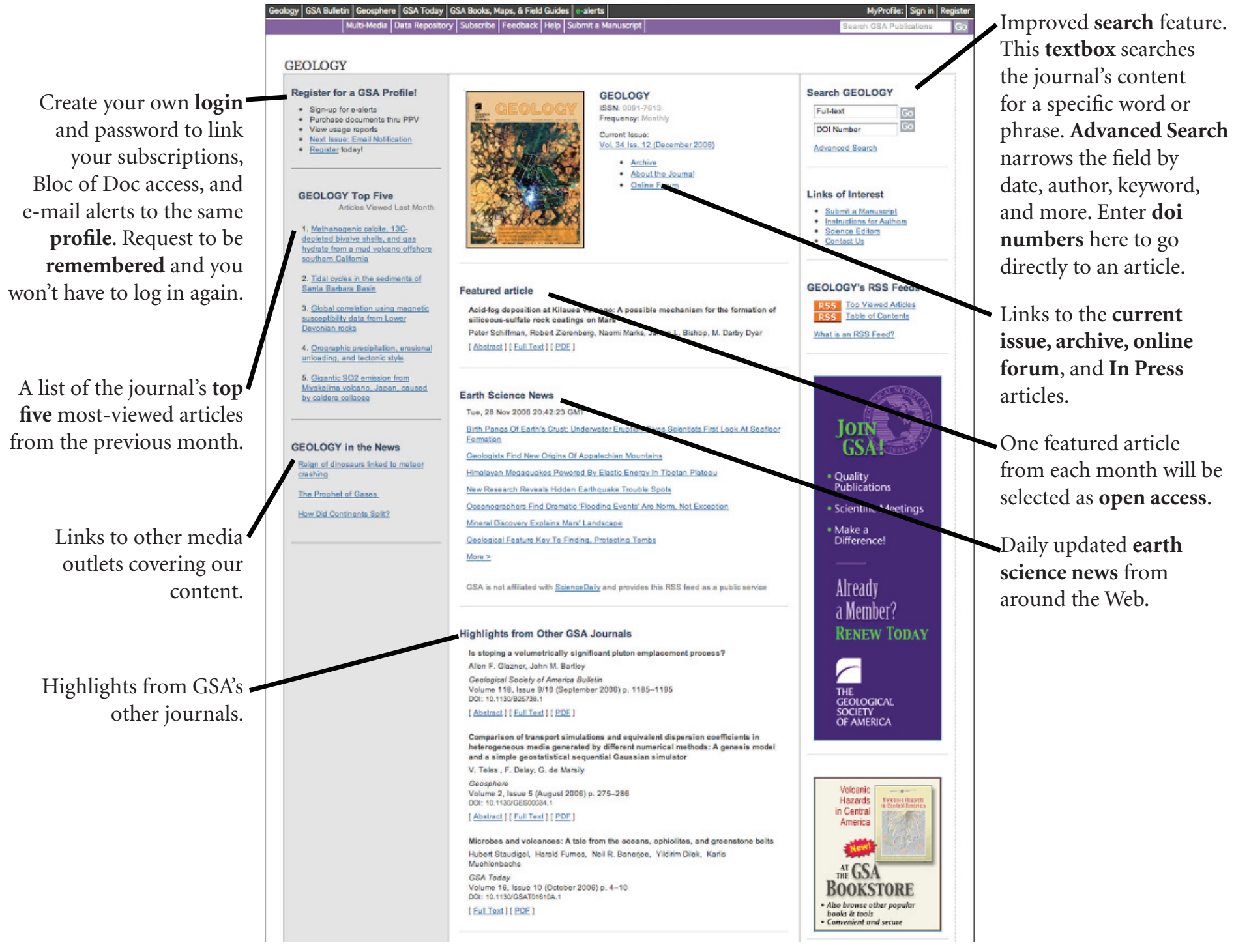

THE GEOLOGICAL SOCIETY

OF AMERICA

SCIENCE - STEWARDSHIP - SERVICE

Additional improvements have been made to the article and table of contents pages, such as

the ability to search Google ${ }^{\mathrm{TM}}$ Scholar for other articles by the same author.

We've tried to create an error-free site, but if we haven't please contact us at

editing@geosociety.org to share your ideas and corrections. 


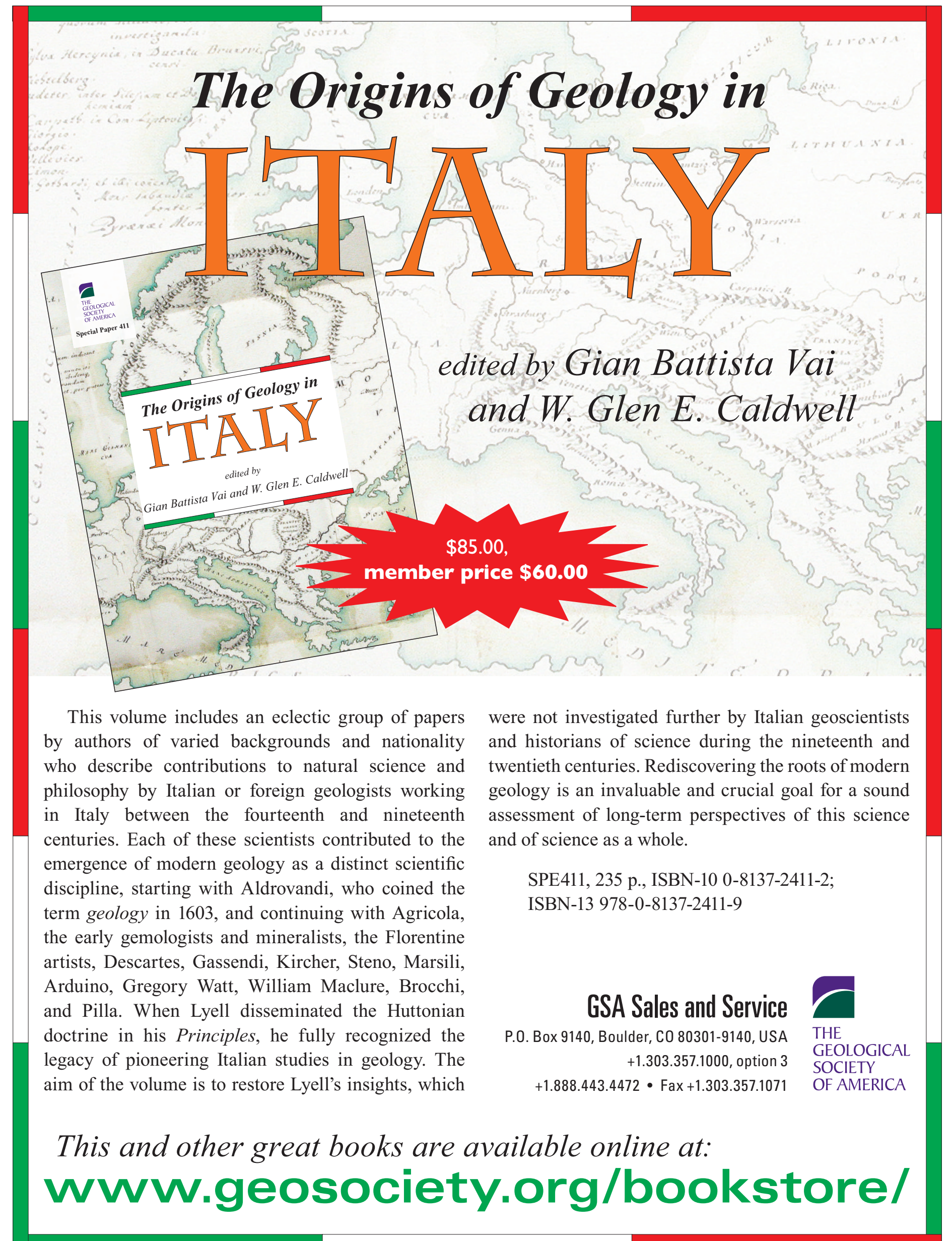

